\title{
Uncovering Seams in Distributed Play of Tabletop Role-Playing Games
}

\author{
Andrew M. Webb \\ CWI \\ Amsterdam, Netherlands \\ amwebb@acm.org \\ Pablo Cesar \\ CWI \\ Delft University of Technology \\ Amsterdam, Netherlands \\ P.S.Cesar@cwi.nl
}

Permission to make digital or hard copies of part or all of this work for personal or classroom use is granted without fee provided that copies are not made or distributed for profft or commercial advantage and that coples bear this notice and the full citation on the first page. Copyrights tor third party compc

CHI PLAY EA '19, October 22-25, 2019, Barcelona, Spain

Copyright is held by the owner/author(s).

15-6871-1/19/10.

https://doi.org/10.1145/3341215.3356253

\begin{abstract}
We uncover how geographically distributed players of tabletop role-playing games engage narrative, ludic, and social aspects of play. Our existing understandings of tabletop role-playing games are centered around co-located play on physical tabletops. Yet, online play is increasingly popular. We interviewed 14 players, experienced with online virtual tabletops. Our findings reveal the seams - points where media, activities, and technology intersect-within virtual tabletop environments that enable distributed players to shift among collaborative storytelling, applying game rules and mechanics, and socially interacting with each other.
\end{abstract}

\section{CCS Concepts}

•Human-centered computing $\rightarrow$ Ethnographic studies;

\section{Author Keywords}

Dungeons \& Dragons; narrativity; virtual tabletop; Roll20

\section{Introduction}

Tabletop role-playing games, such as Dungeons \& Dragons, are seeing a resurgence in popular culture [2]. In these games, players take on the roles of fictional characters as they collaboratively create stories while sitting around a table. Players interact with various physical objects, such as dice, character sheets, books, and maps. They engage in social interactions with each other, such as speaking 


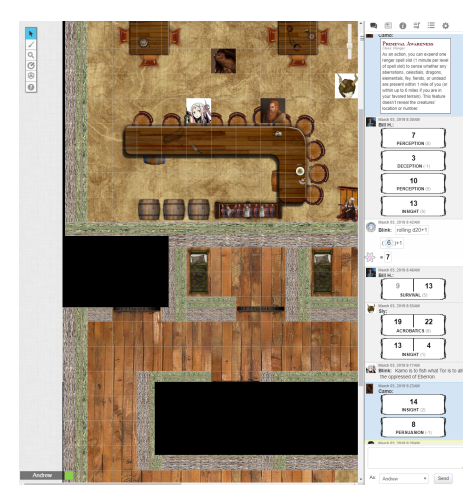

Figure 1: The Roll20 interface: tool palette in top-left; virtual tabletop in middle; and chat on right with automated dice roll results, character ability cards, and player messages. in-character, discussing game rules, and making jokes. Tabletop role-playing games originated with and evolved for decades around co-located players sitting at physical tabletops $[6,8,10,13]$. Today, geographically distributed players from all of the world join together to play these games via virtual tabletops, such as Roll20 [17] and Fantasy Grounds [7]. While co-located play is well studied, we lack understandings of how virtual tabletops and distributed players affect play experiences.

This research conducts an ethnographic study to better understand how technologies and media support distributed play of tabletop role-playing games. We first discuss related work, and then present our methodology. We report initial findings from interviews with active, regular players that use virtual tabletops for distributed play. We conclude with implications of our findings and future work.

\section{Background}

We ground our work in prior ethnographic studies of tabletop role-playing games $[6,8,10,14]$. We discuss $\mathrm{HCl}$ research that augments experiences of co-located play with technology $[4,12,15]$, and detail features of Roll20, a commercial virtual tabletop used by our participants.

Frames of Experience in Tabletop Role-Playing Games Fine [8] identifies three frames of experience in tabletop role-playing games: (1) the primary, social framework that people use to make sense of the real world, such as chatting about life; (2) the game context governed by game rules and mechanics, including discussing interpretation of rules or asking players to roll dice; and (3) the game world in which players' characters act, including speaking in-character or describing a character's actions.

In considering aspects of narrativity in tabletop role-playing games, Mackay [13] further breaks down the game world frame into three separate frames based on narrative, constative, and performative types of speech. Cover [6] argues that constative and performative speech are both used to form the narrative, and therefore Mackay's three frames constitute a single narrative frame.

Building on Fine and Mackay, Cover identifies three frames of experience with differing (decreasing) levels of narrativity:

- Narrative frame: "players create textual narrative world."

- Game frame: "players engage in game play and are immersed in the game world."

- Social frame: "players interact in a social setting."

Fine, Mackay, and Cover point out how players fluidly shift among these different frames. At times, frames are shortlived, multiple shifts occurring even within the same sentence. Other times, frames are stable, such as when players, using their characters' voices, engage in conversation that forms part of the narrative. Their discussions of frames center around spoken language. Our study uncovers aspects of how technology and media help shape these frames and the shifts between them in distributed play.

\section{Augmenting Tabletop Role-Playing Games}

Prior work on augmenting play experiences develops hybrid, mixed-reality interfaces [1] that weave together physical and virtual representations for co-located play. The STARS platform combines digital devices that show aspects of the virtual world, such as maps or character details, with physical artifacts already present in these games, such as dice and figurines [15]. Lindley and Eladhari conceive trans-reality role-playing games that support combined play across live action, tabletop, and computer-based games [12]. WEARPG incorporates wearables to support movement-based play in tabletop role-playing games [4]. 


\begin{tabular}{|lll} 
Id & $\begin{array}{l}\text { GM or } \\
\text { PC }\end{array}$ & Games \\
\hline P1 & GM & $\begin{array}{l}\text { D\&D 5e, } \\
\text { Stars Without } \\
\text { Number }\end{array}$ \\
\hline P2 & PC & D\&D 5e \\
P3 & GM & D\&D 5e \\
\hline P4 & Both & D\&D 5e \\
\hline P5 & Both & D\&D 5e \\
\hline P6 & GM & Shadowrun \\
\hline P7 & Both & Shadowrun, \\
& & Call of \\
& & Cthulhu \\
\hline P8 & GM & D\&D 5e \\
\hline P9 & Both & D\&D 5e \\
\hline P10 & GM & D\&D 5e, \\
& & Werewolf \\
\hline P11 & Both & D\&D 5e \\
\hline P12 & GM & Pathfinder \\
\hline P13 & Both & D\&D 5e \\
\hline P14 & PC & D\&D 5e \\
\hline
\end{tabular}

Table 1: The play roles of participants-game master (GM), player character (PC), or both-and the games discussed.

\section{Roll20: Virtual Tabletop}

We selected the popular virtual tabletop, Roll20, for the focus of our investigation. The basic Roll20 interface includes a gridded 2D canvas representing the 'tabletop', a text chat, and a tool palette (Figure 1). The canvas provides layers for compositing visual media, such as maps and character tokens. Text chat contents include outcomes for automated dice rolls, cards describing character abilities, and player messages. Players can emote their characters state or privately message another player using commands in the text chat. The tool palette provides a set of tools for interacting with the canvas, including panning and zooming, moving tokens, measuring distances, and drawing annotations.

\section{Method}

We conducted a qualitative study, interviewing players of tabletop role-playing games with regular experience (at least once every 1-2 weeks) in distributed play.

\section{Participants}

We recruited fourteen participants (Table 1 ) through a survey posted on the Roll20 subreddit [18]. Twelve players reported playing as the game master or GM-a specific role in popular tabletop role-playing games where the player acts as referee and orchestrator of the collaborative storytelling experience, setting scenes, creating tension, and reacting to the actions of other players. Additionally, six of those twelve played in games as an individual character rather than the GM. Two players never played as the GM.

\section{Procedure}

We conducted fourteen individual interviews. We used Mackay's [14] variation of Flanagan's critical incident interview technique [9], in which we ask participants to recoun their most recent play session to draw out specific instances of their experiences. This technique favors detailed descrip- tions of defined situations over global statements about general use, grounding the participants in their experiences rather than asking them to speak generally or abstractly about their practice. Interviews lasted 55-105 minutes.

\section{Data Collection}

Interviews took place using participants preferred telecommunication software (e.g., Skype, Discord). We recorded video and audio of the interview using OBS [16]. We collected approximately 17 hours of video in total.

\section{Data Analysis}

We transcribed interviews. We then performed an initial open coding for thematic analysis [3] of the transcriptions. While a number of codes emerged, we selectively report on those related to frames of experience and the shifts between frames as mediated by computing technology.

\section{Results and Discussion}

Our findings identify seams occurring as virtual tabletop functionality, media, and player appropriations of the two intersect with frames of experience. Chalmers defines a seam as a "break, gap, or 'loss in translation' in a number of tools or media designed for use together as a uniformly and unproblematically experienced whole" [5]. While many of the tools and media that participants report using were not designed for use together, participants created 'setups' that enabled combined use of the tools and media to support holistic play experiences. Perhaps more appropriately, Kuznetsov et al. [11] define seams as "points at which different materials, practices, categories, etc., intersect, sometimes in unexpected ways."

\section{Narrative Frame}

In distributed play, we find that the narrative frame connects across voice communication, music, text chat, and virtual spaces. All participants report using both voice and text 


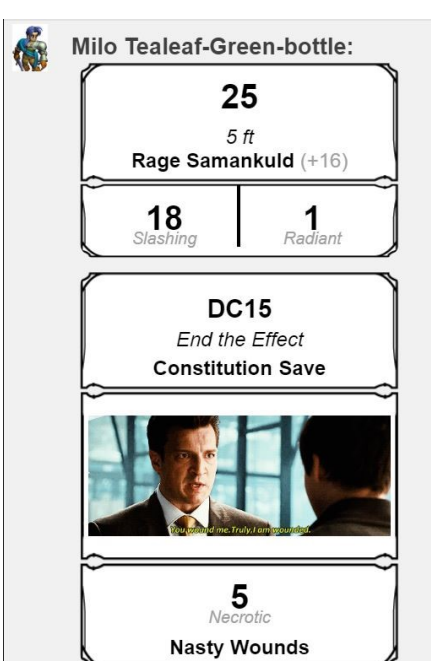

Figure 2: Example of players integrating memes into spell or ability cards presented in Roll20 text chat. to speak in-character. Most participants (10) report using Discord, a free communication tool for gamers that combines calling features of Skype with text chatting features of Slack. While play typically occurs in a channel with all players, on certain occasions, several players may separate from the group into a private channel. For example, half the participants, as a GM, report taking a player aside when that player's character goes on a solo endeavour, which is outside the purview of the other players' characters. This separation keeps the solo endeavour a secret from the other players, and it allows the other players to chat with each other without disrupting play. This action creates a hard seam in audio communication and narrative where players are separated across channels without any feedback of what is happening in other channels.

Most participants (8) report using sound in their games.

They describe using Roll20's Jukebox, which enables synchronized playback of music and sound effects. Participants report how music and sound effects add to the immersive experience. They find the integrated ability to play music and sound effects in Roll20 fairly seamless. Several participants (3) express dissatisfaction when a convenient audio sharing service was recently removed from the platform.

Music and sound effects can serve the narrative, drawing players attention towards aspects of the story.

P3: "There were some undead fighting the party, and there was a mage that was hurt and bleeding behind them. And so, when they were fighting, at some point I played a sound over the music, 'Please, help me! Please, help me!' So, they basically heard this. They were like, 'Holy shit! What's going on?' Then, they look a little further, and they saw there was a man on the ground. That's why the sound system in Roll20 is amazing!"
All participants report using the text chat within the virtual tabletop. They role play their characters in this text chat. They use commands (e.g., /em in Roll20) that allow players to emote (in third-person) about their character's actions or attitudes towards other characters. By using these commands, players separate narrative discourse from social messages and rules discussion in the text chat.

P6: "Some of my players are ardent text role players, so when the they needed to convey that their character was sending a text message to somebody, they would do lem and then say, character name, colon, the text that they are sending, sent to $x$ character. And it just looks significantly nicer than just putting it in the regular chat. And plus, then it's actually been useful for me, as a GM. Having multiple characters be texted by multiple other characters, I can lem and show that this is an in-universe thing that is happening."

All participants describe using private messages to communicate information directly to other players. GMs use this to reveal details to one player that their character would know without informing the other players. Players use it to keep their plans hidden from the GM. Roll20 supports private messaging via a chat command (/whisper) where the player must specify the target and message. Most participants (10) report using the whisper command. It requires issuing the command with every message. Alternatively, Discord supports private conversations, which participants favor when having lengthier discussions.

Participants report creating multiple text channels (supported in Discord) for role playing, including ones for speaking in-character, and discussing the lore of the game world. 
P9-A: "We had a encounter a couple of sessions back where a dryad was in a particular tree. During the night when they were sleeping, I rolled that this dryad would do something. So I usually I just say, 'Yeah, okay, night goes on, eventually.' So, when I say, 'Yeah, so we go to this map', this player who is just sitting watch, then they know that something is going to happen. So I dragged them over to this map that had a forest clearing with some trees to either sides. And I had put some dryads on the GM layer that the players couldn't see those in those trees. And I just asked them to describe what they were doing when they were setting up the camp or that kind of stuff. And eventually someone said something along the lines, 'Yeah, l'm going to chop some firewood.' So I kind of made up this story that the dryads were angry that they were stealing that woods and burning it. So during that night, they were sitting around the campfire with one of them, keeping watch. And then I just bought those dryads from the GM layer onto the player layer so they could see them."
P2: "We've got an in-game chat text channel, where if we are not actually playing the game and somebody wants to say something in character, we do it within that chat channel. And, that captures stuff like, 'Hey, when we wake up from our short rest here, how about we all travel to this next village.'. . Another channel is lore questions. In here, we had questions about who the rulers of the area were [and] seeing a lot of troops on the road. It's not really incharacter, but it's specific to what the GM has put before that we should be able to figure out."

GMs report creating virtual spaces to represent different locations in the game world. In Roll20, they use a feature called Pages. Pages are presented in Roll20's 2D canvas. A hard seam exists between each Page. Page transitions are initiated by the GM with a visible load screen for all players. These transitions can function towards narrative tension, indicating to the players that an encounter (potentially combat-related) or something else of importance is about to occur (see P9-A quote).

\section{Social Frame}

The social frame connects across voice communication, text chat, and video. Participants report engaging in conversations about their lives, often at the start of a session. During play, just as with co-located sessions, players interleave social discussions, such as out-of-character jokes or pop culture references. This occurs in text chat as well. Players type messages, such as "brb" (be right back), to convey social cues about their presence. Participants describe creating general text channels for similar discussions, posting memes, or scheduling upcoming play sessions.

Several participants (4) report posting images and other non-textual media in text chat during play sessions (see
P9-B quote). Often times these postings are inspired from events taking place in the narrative, but shift away to a social frame using content from the real world for humor. Since they are posted in a text chat, they do not directly disrupt voice communications. Participants describe inserting images into ability cards or outcomes of automated dice rolls, such as memes for humor (Figure 2), intersecting the social and game frames.

Four participants report using video of faces. Only one uses video within Roll20 to position the faces of other players near his own webcam allowing him to look at the camera while also observing their responses. The others use video in Discord or Skype, located in a separate window. Two participants report preference towards not using video as they feel it makes the experience more immersive when only hearing someone's voice. All participants that did not use video note that this makes them less aware of social cues, such as the attentiveness of other players.

\section{Game Frame}

The game frame connects across voice communication, text chat, and virtual spaces. Participants discuss rules and strategy by talking. These discussions also take place in text chat. They may occur in secret using private messaging, something that is harder to hide in co-located play.

P2: "If you are sitting at a table, and you are like, "Everybody else don't pay attention while I whisper to this person." Everybody else is like, 'What the hell are they whispering about?!' Where in Roll20, you can be like, 'Hey, on the down low, if this guy twitches, lets attack."

All participants report how the virtual tabletop streamlined parts of dealing with game rules, such as rolling dice, keeping track of status effects, and establishing turn order. They 
P9-B: "One of my players in that game is really into into cooking for some reason. It's in his backstory, so whenever we stopped in a city to buy rations or something like that, he actually would spend more money to buy some expensive rations, premium rations, stuff like that... And his bag of holding is getting a bit light. So he says, 'Yeah, I've only got potatoes now.' And then the other guys were like, 'Oh, but you can do so much with potatoes.' Then, they actually posted pictures of all the different dishes you can make with potatoes, all that kind of stuff. So we were kind of like semi-serious in voice. And then every once in a while someone would post a new picture of hash browns or something like that. And then people would start laughing." all use the built-in dice rollers of virtual tabletops. Results are displayed in the text chat. The GMs hide the results of their rolls. In some virtual tabletops, while results are hidden, the players are informed that dice were rolled. To counteract this, one GM would privately roll physical dice when he didn't want the players to know a roll was happening. Thus, as game rules become streamlined, players gain less control over how they are administered.

P8: "I always have a set of dice. Because when I, as a GM, roll, it shows me roll, and you just see. They see a like a shadow dice. They don't actually see what it is. But they can see that I'm rolling. Sometimes I want to roll, I don't want them to know that I'm rolling at all. And so I'll just take out my dice, and l'll roll."

Just as participants created role playing text channels for narrative frame, they similarly create text channels for discussing game rules and questions about what is allowed

\section{Implications for Virtual Tabletop Design}

Our interviews reveal how participants use tools and media as they engage in distributed play. While virtual tabletops, such as Roll20, functionally support audio, video, and text communication, participants choose to use other communication tools, which better support shifting of frames and have fewer technical breakdowns. We identify the following implications for designing virtual tabletops for distributed play of tabletop role-playing games:

Provide seamful and organizable communication channels. Despite the presence of text chat in Roll20, many participants opted to use Discord for out-of-character comments, private messaging, and lengthier in-character conversations. Roll20 provides a single text chat where all textual communication takes place. Similar to Discord, virtual tabletops could allow multiple communication channels, of not only text, but additionally audio and video, of which players can categorize for distinct purposes, such as ones for narrative, game, and social frames. Feedback about player presence within these varied channels becomes important for seamful design.

Enrich narrative and social frames via seamless integration of external media. Participants made use of images, animated GIFs, and music. Participants valued the ability to directly integrate media into the play environment, such as inserting memes into dice roll outcomes or adding sound effects in response to character actions. This enables fluid shifting between frames of experience, similar to what occurs in in spoken language with these games.

\section{Support flexible control over the seams of the game} frame. Streamlining how game rules are administered by the virtual tabletop could help players remain more in the narrative and social frames, which has potential value for engagement. However, a lack of control over how rules and outcomes are presented may instead bring players' attention towards the game frame. Visibility controls are needed to allow players to decide when it is appropriate to reveal.

\section{Conclusion}

Our findings reveal how frames of experience intersect tools and media in distributed play of tabletop role-playing games. We elicited perceived experiences through interviews. Future work will validate our findings through observations of actual practice with multiple virtual tabletops. We plan to conduct an observational study, as well as, analyze video content of distributed play published online via Twitch and YouTube. We foresee design implications for distributed collaboration environments and live-streaming experiences, in which media, activities, and technology intersect as participants engage with each other. 


\section{REFERENCES}

1. Steve Benford, Carsten Magerkurth, and Peter Ljungstrand. 2005. Bridging the Physical and Digital in Pervasive Gaming. Commun. ACM 48, 3 (March 2005), 54-57. DOI :

http://dx.doi.org/10.1145/1047671.1047704

2. Geoff Boucher. 2018. Like a wily old wizard, 'Dungeons \& Dragons' shows it has enduring magic. (July 2018). https://www . latimes. com/entertainment/movies/ la-et-hc-dungeons-dragons-20180730-story .html [Online; posted 31-July-2018].

3. Virginia Braun and Victoria Clarke. 2006. Using thematic analysis in psychology. Qualitative Research in Psychology 3, 2 (2006), 77-101. DOI :

http://dx.doi.org/10.1191/1478088706qp063oa

4. Oğuz Turan Buruk and Oğuzhan Özcan. 2018.

Extracting Design Guidelines for Wearables and Movement in Tabletop Role-Playing Games via a Research Through Design Process. In Proceedings of the $2018 \mathrm{CHI}$ Conference on Human Factors in Computing Systems (CHI '18). ACM, New York, NY, USA, Article 513, 13 pages. DOI :

http://dx.doi.org/10.1145/3173574.3174087

5. Matthew Chalmers, Marek Bell, Barry Brown, Malcolm Hall, Scott Sherwood, and Paul Tennent. 2005. Gaming on the Edge: Using Seams in Ubicomp Games. In Proceedings of the 2005 ACM SIGCHI International Conference on Advances in Computer Entertainment Technology (ACE '05). ACM, New York, NY, USA, 306-309. DOI :

http://dx.doi.org/10.1145/1178477.1178533
6. Jennifer Grouling Cover. 2014. The Creation of Narrative in Tabletop Role-Playing Games. McFarland \& Company, Inc.

7. Fantasy Grounds. https ://www . fantasygrounds .com

8. Gary Allen Fine. 1983. Shared Fantasy: Role Playing Games as Social Worlds. University of Chicago Press.

9. John C. Flanagan. 1954. The Critical Incident Technique. Psychological Bulletin 51, 4 (1954), 327.

10. Antero Garcia. 2019. Gaming Literacies: Spatiality, Materiality, and Analog Learning in a Digital Age. Reading Research Quarterly 0, 0 (2019), 1-19. DOI : http://dx.doi.org/10.1002/rrq. 260

11. Stacey Kuznetsov, Alex S. Taylor, Tim Regan, Nicolas Villar, and Eric Paulos. 2012. At the Seams: DIYbio and Opportunities for $\mathrm{HCl}$. In Proceedings of the Designing Interactive Systems Conference (DIS '12). ACM, New York, NY, USA, 258-267. DOI : http://dx.doi.org/10.1145/2317956.2317997

12. Craig Lindley. 2005. Narrative structure in trans-reality role-playing games: Integrating story construction from live action, table top and computer-based role-playing games. Proceedings of Digital Games Research Association (DiGRA) 2005 Conference (2005).

13. Daniel Mackay. 2001. The Fantasy Role-Playing Game: A New Performing Art. McFarland \& Company, Inc.

14. Wendy E. Mackay. 2002. Using video to support interaction design. DVD Tutorial, CHI 2, 5 (2002). 
15. Carsten Magerkurth, Maral Memisoglu, Timo Engelke, and Norbert Streitz. 2004. Towards the Next

Generation of Tabletop Gaming Experiences. In

Proceedings of Graphics Interface 2004 (Gl '04).

Canadian Human-Computer Communications Society, School of Computer Science, University of Waterloo,

Waterloo, Ontario, Canada, 73-80. http: //dl. acm.org/citation. cfm?id=1006058. 1006068

16. Open Broadcaster Software. https://obsproject.com

17. Roll20. https://roll20.net

18. Roll20 subreddit. https://reddit. com/r/roll20 